\title{
Invloeden van de markt op de kwaliteit van accountantscontrole
}

\author{
Prof. J.H. Blokdijk
}

\section{Inleiding}

Tijdens de Accountantsdag 1992 heeft het Bestuur van het Nederlands Instituut van Registeraccountants een discussienota over de kwaliteit van de beroepsuitoefening het licht doen zien. Deze nota is gebaseerd op een rapport van een Instituutscommissie die schrijver dezes heeft mogen leiden. Daarin is uiteraard aandacht gegeven aan de eisen die worden gesteld aan individuele beoefenaren van het openbaar accountantsberoep en aan samenwerkingsverbanden daarvan (accountantsmaatschappen).

Daarnaast zijn ook expliciet in beschouwing genomen de mogelijke gevolgen voor de kwaliteit van accountantsarbeid van het feit dat (samenwerkingsverbanden van) accountants met elkaar in concurrentie treden op een markt; naar mijn waarneming heeft het NIVRA hiermee een wereldprimeur. Aan laatstbedoelde mogelijke gevolgen wil ik in dit artikel een beschouwing wijden.

Dit nieuwe terrein is betreden door een commissie die naast ondergetekende bestond uit de registeraccountants $H$. Baas, Drs. W.J.M. Dill, Prof. Drs. J.C.E. van Kollenburg, Prof. Mr. Dr. F. van der Wel en A.E.H. van Wielink, bijgestaan door Mr. L.B. Bijl. Een dergelijke verkenning van een nieuw gebied leidt niet steeds tot gedachten waarover bij alle betrokkenen elke aarzeling is uitgebannen. Daarenboven heeft het Instituutsbestuur een eigen verantwoordelijkheid: ook al wordt een idee in een discussienota neergelegd, dan krijgt dit toch een zeker gezag mee; een bestuur dat zijn autoriteit met prudentie hanteert, kan met het volste recht concluderen dat bepaalde gedachten dat voorlopige gezag (nog) niet verdienen. Om deze ideeën dan verder te laten rijpen, is het zinvol ze onder persoonlijke titel voor te leggen aan de gemeenschap van accountants en degenen die belang stellen in accountancy.

Tenslotte heeft voortgezette bezinning enkele nieuwe gedachten bij mij doen opkomen waarvan ik het evenzeer zinvol acht ze aan de toets der kritiek te onderwerpen.

\section{Concurrentie en lrwaliteit}

Aan het begrip 'kwaliteit' wijdt de discussienota (NIVRA 1992) in paragraaf 2.1 een beschouwing die ik hier niet zal herhalen. Een belangrijke conclusie is: de hoogste kwaliteit is het overtreffen van de verwachtingen van de afnemer. Die verwachtingen zijn uiteraard tijdgebonden; de discussienota concludeert dan ook dat kwaliteit een relatief begrip is: de inhoud verschuift in de tijd.

Vrijwel overal ter wereld hebben opdrachtgevers keuze uit verschillende aanbieders van accountantsdiensten. Dezen trachten elk voldoende opdrachten te verwerven om in hun levensonderhoud te voorzien dan wel hun welstand te verhogen. Zij zijn dus ondernemers die in concurrentie treden.

Prof. J.H. Blokdijk, registeraccountant, is directeur van J.H. Blokdijk Advies B.V. en adviseur van ondernemingen en accountants. Hoogleraar toegepaste Accountantscontrole aan de Vrije Universiteit Amsterdam. Heeft vele vaktechnische functies bij het NIvRA vervuld. 
Bij een beschouwing die 'kwaliteit' in de context van de markt, en dus van concurrentie, plaatst, is de vraag uiteraard: hoe beïnvloedt de concurrentie de kwaliteit in de loop van de tijd? Worden de produkten en diensten door concurrentie beter of slechter?

Op de kortere termijn kan het optreden op een markt kwaliteitsverlagend werken, omdat van concurrentie een prijsdrukkend effect kan uitgaan. Dit kan leiden tot het leveren van produkten of diensten van een lagere kwaliteit. Ook accountants staan uiteraard aan deze economische krachten bloot; dit wordt voor een belangrijk deel van hun diensten nog versterkt door een omstandigheid die ik in de volgende paragraaf van dit artikel nader bespreek. Op de kortere termijn kan het feit dat accountants op een markt in concurrentie treden, de kwaliteit dus bedreigen.

Op de langere termijn, zo zou ik willen stellen, werkt concurrentie in het algemeen kwaliteitsbevorderend. Een aanbieder van goederen of diensten is meestal méér gebaat bij het leveren van een hoge kwaliteit met behoud of verhoging van de prijs dan bij prijsverlaging gepaard aan een lagere kwaliteit. Méér concurrentie betekent een sterker streven naar kwaliteitsverbetering.

De mate van concurrentie hangt onder meer samen met de openheid van een economie. Daar waar nieuwe aanbieders geweerd worden, is minder concurrentie dan daar waar hun weinig in de weg gelegd wordt. In een open economie kunnen zich relatief gemakkelijk nieuwe, ook buitenlandse aanbieders van allerlei goederen en diensten vestigen: er treedt in deze ondernemingen vaker scheiding tussen eigendom en leiding op dan bij de traditionele, vaak gesloten nationale ondernemingen, zoals de staatsondernemingen in Oost-Europa en de familieconcerns in Latijns Amerika. Door scheiding van eigendom en leiding ontstaat een grotere behoefte aan accountantsdiensten. Als de toetreding tot het beroep niet kunstmatig wordt beperkt, komen er veel aanbieders van accountantsdiensten, die er belang bij hebben op kwaliteit te concurreren.

Ik durf daarom de stelling te poneren dat de kwa- liteit van het accountantsberoep in enig land rechtevenredig is met de openheid van de economie van dat land, althans in grote trekken en op de wat langere termijn. Deze stelling zou kunnen verklaren waarom de kwaliteit van het Nederlandse accountantsberoep reeds geruime tijd gunstig afsteekt bij die in de ons omringende landen op het vasteland van Europa, waar de economieën van oudsher veel sterker zijn gedomineerd door de banken en de rijke families dan ten onzent. Als de stelling juist is, verminderen de kwaliteitsverschillen naarmate de economieën verder open gaan, hetgeen door de EG wordt nagestreefd.

Ik besef dat de bevestiging of de ontkrachting van deze stelling een onderzoek van zodanige reikwijdte en diepgang vergt, dat de succesvolle uitvoering mogelijk met een promotie bekroond zou kunnen worden. Zeker tot dat moment kan de stelling bestreden worden. Zo zal ten aanzien van de aanbodzijde van de markt voor accountantsdiensten menig lezer mij tegenwerpen dat de toetreding tot het accountantsberoep in Nederland stellig niet gemakkelijk is. Dat moge zo zijn, maar in Nederland wordt ieder die het accountantsdiploma heeft behaald, ingeschreven in het accountantsregister, tenzij hij of zij zich ernstig heeft misdragen. In meer gesloten economieën gaat dat anders toe: zo was tot in de jaren tachtig het accountantsexamen in Spanje een vergelijkend examen, waarbij het aantal geslaagden werd bepaald door de behoefte van het accountantsgilde de markt voor hun diensten te beschermen.

Een andere gevolgtrekking die uit de eerder geponeerde stelling is te maken, is dat wetgeving op de wat langere termijn geen invloed heeft op de kwaliteit van het accountantsberoep. Daarvoor zijn vele voorbeelden: in menig economisch minder ontwikkeld land werd op enig moment een (veel) hoger peil van accountantscontrole geïntroduceerd door buitenlandse accountantskantoren, die in het kielzog van buitenlandse investeerders binnenkwamen. Hogere normen van accountantscontrole werden dan eerst toegepast bij de controle van jaarrekeningen van aldaar gevestigde ondernemingen van buitenlandse herkomst, dus in de sectoren van de economie die althans 


\section{MAB}

enigszins opengesteld waren. De kwaliteit waar de markt om vroeg, werd dus ook aangeboden. Om te kunnen blijven concurreren in een economie die groeide door de buitenlandse investeringen, moesten de grotere lokale accountantskantoren hun kwaliteit verhogen. Dat is dan ook vaak geschied, ondanks povere wetgeving of zelfs het ontbreken daarvan. Zo is het in zekere zin in Nederland óók gegaan, zij het dat hier de ontwikkeling meer door de notering van Nederlandse ondernemingen aan buitenlandse beurzen dan door buitenlandse investeringen hier te lande is gestimuleerd.

Dit betekent voorts, dat de wetgever de feitelijke kwaliteit niet omlaag kan verordonneren. De kwaliteit waar de markt om vraagt, wordt geleverd, zoals ook de vaderlandse geschiedenis over de periode vóór de inwerkingtreding van de Wet op de Registeraccountants heeft geleerd. De recente ontwikkelingen rond de accountantswetgeving behoeven dus de accountants op wat langere termijn geen zorgen te baren.

\section{Kwaliteit in het openbare accountantsberoep}

Op de markt bieden openbare accountants diensten aan die te onderscheiden zijn in:

- diensten die mede, en vaak vooral, op derden in een al dan niet besloten kring zijn gericht, en

- diensten die uitsluitend voor de opdrachtgever zijn bestemd.

(NIvRA 1992, paragraaf 2.3.)

Het typische accountantsprobleem heeft geen betrekking op laatstgenoemde diensten: daarbij onderscheiden accountants zich niet van velerlei andere vrije beroepen. Over de kwaliteit van dergelijke dienstverlening is veel literatuur beschikbaar, zie bijvoorbeeld Kunst en Lemmink (1992); daarom zal ik hier thans niet op ingaan.

Het vraagstuk betreft de op derden gerichte diensten, waarvan de controle van jaarrekeningen de belangrijkste is. Ik beperk mij in dit artikel tot de controle van en de verklaring bij jaarrekeningen, omdat dit de leesbaarheid van deze beschouwing bevordert; bij andere op derden gerichte diensten, zoals de beoordeling en de samenstelling van jaarrekeningen en bij de controle van andere verantwoordingen, bestaan tot op zekere hoogte soortgelijke vraagstukken.

Aangezien de accountantsverklaring bij een jaarrekening bestemd is om aan derden, al dan niet in besloten kring, te worden overgelegd, dienen de rationele behoeften van deze derden doorslaggevend te zijn voor de kwaliteit van de daaraan ten grondslag liggende werkzaamheden; derden baseren vaak allerlei belangrijke beslissingen op jaarrekeningen en hebben dus een legitiem belang bij de kwaliteit van het onderzoek daarvan.

De opdracht tot de controle van de jaarrekening wordt vrijwel altijd gegeven door degene die de jaarrekening aan bedoelde derden dient over te leggen; de opdrachtgever is ook vrijwel steeds degene die voor deze dienst van de accountant betaalt. Hij heeft dan ook belang bij de laagst mogelijke prijs voor die dienst, hetgeen betekent dat hij de laagst mogelijke kwaliteit zal verlangen waarbij hij zijn doel, een goedkeurende accountantsverklaring, nog bereikt.

Samengevat: de gebruiker van de accountantsverklaring verwacht een 'dienst' van ten minste toereikende kwaliteit, de opdrachtgever koopt een 'produkt' tegen de laagste prijs. De uitkomst in een stabiele situatie is, dat de laagste voor derden nog aanvaardbare kwaliteit gelijk wordt aan de hoogste door de opdrachtgever aanvaarde kwaliteit: minimum = maximum! (NIvRA 1992, paragraaf 2.4.)

Daar komt de omstandigheid bij waarop in het vorige hoofdstuk van dit artikel werd geduid. Deze is gelegen in het feit dat van controlewerk moeilijk te zien is of het goed is gedaan. Als het controle-object geen onvolkomenheden bevat, worden die natuurlijk ook niet aangetroffen. Als echter geen onvolkomenheden worden vastgesteld, kan niet met volkomen zekerheid gezegd worden dat deze er ook niet zijn: de controleur kan zijn werk onjuist hebben ingericht, of de onvolkomenheden over het hoofd hebben gezien.

Aan de accountantsverklaring is echter niet te 
zien of de controle al dan niet goed is opgezet en uitgevoerd. Dit verschijnsel kan bij de accountant de neiging doen ontstaan bij verschil van inzicht toch een goedkeurende verklaring te geven dan wel daarvoor werkzaamheden van minder dan de maatschappelijk aanvaardbare minimumkwaliteit te leveren. Hierdoor kan dus kwaliteitsverlaging ontstaan.

Nu laat het feit dat accountants in concurrentie op een markt opereren, de opdrachtgever keus: hij kan zich bij verschil van inzicht over kwaliteit en/of prijs tot een andere accountant wenden. Daartoe zal hij geneigd zijn indien hij een andere dan een goedkeurende accountantsverklaring dreigt te krijgen, of indien hij de door de accountant geleverde kwaliteit te hoog en dus te duur acht.

Het vorengeschetste samenstel van verschijnselen kan leiden tot kwaliteitsverschillen tussen accountants. Die zijn bij op derden gerichte opdrachten in beginsel ongewenst; immers, daarbij zijn - zoals zojuist geconstateerd - de minimumkwaliteit en de maximumkwaliteit in een stabiele situatie aan elkaar gelijk. Daardoor kunnen kwaliteitsverschillen licht leiden tot kwaliteitserosie: een lagere dan in het maatschappelijk verkeer aanvaardbare kwaliteit.

Daar accountants in de markt autonoom kunnen optreden, zijn deze ongunstige ontwikkelingen in beginsel slechts tegen te gaan door een beroepsorganisatie; deze moet dan beschikken over kennis van zaken en over een zekere macht. Dat een beroepsorganisatie voor accountants onontbeerlijk is, leert ook de geschiedenis. Bij de totstandkoming van accountantsorganisaties is kwaliteit altijd één van de belangrijkste drijfveren geweest; zo beschrijft De Vries in zijn boek over de geschiedenis van het Nederlandse accountantsberoep in de jaren 1895-1935 het verschijnsel van de 'cascade', waarbij steeds meer accountantsverenigingen werden opgericht met steeds lagere eisen aan de kwaliteit (De Vries 1985, onder andere p. 74; zie ook De Bruyne 1980).

De Nederlandse beroepsorganisatie heeft dan ook reeds lang aandacht voor kwaliteit, en bevordert die door regelgeving. In de eerdergenoemde discussienota (NIvRA 1992) zijn ook beschouwin- gen gewijd aan mogelijke verdergaande maatregelen, zoals een keurmerk voor en/of collegiale toetsing van samenwerkingsverbanden van accountants (paragraaf 4.4). Al deze maatregelen richten zich op het stelse/ van kwaliteitsbevordering in die samenwerkingsverbanden; minder aandacht is besteed aan kwaliteitsverschillen bij afzonderlijke opdrachten. Voor de zojuist genoemde maatregelen zij verwezen naar de discussienota; hierna wordt met name aandacht geschonken aan kwaliteitsverschillen die daarin minder geprononceerd aan de orde zijn gekomen. Daarbij speelt het eerder gesignaleerde feit dat de kwaliteit van de accountantscontrole in beginsel vrijwel nooit uit de accountantsverklaring is af te lezen, opnieuw een belangrijke rol.

\section{Enkele verschijningsvormen van kwaliteitsverschillen}

Eén verschijningsvorm van kwaliteitsverschil is het feit dat verschillende samenwerkingsverbanden van accountants bij de controles van jaarrekeningen uiteenlopende toleranties hanteren en uiteenlopende risico's aanvaarden (NIvRA 1992, paragraaf 4.5, sub a). Deze kwaliteitsverschillen blijven de lezer van accountantsverklaringen onbekend, hetgeen in beginsel een vraagstuk oproept. Of deze verschillen groot zijn, is voor een buitenstaander dan ook niet na te gaan; daardoor is ook niet bekend of hier sprake is van een belangrijk probleem. Het zou door regelgeving op te lossen zijn, zij het dat deze in het huidige tijdsgewricht internationaal gezag zou moeten hebben.

Voorshands ernstiger is de mogelijkheid van kwaliteitserosie. Deze kan plaatsvinden in:

- de jaarverslaggeving, doordat accountants genoegen nemen met een steeds toenemende variëteit van verslaggevingsvormen, waarbij al snel geldt: 'bad accounting drives out good accounting',

en/of in:

- de controle, doordat accountants uit concurrentie-overwegingen genoegen nemen met steeds lagere honoraria, en daarvoor steeds 


\section{MAB}

minder werkzaamheden verrichten: 'bad auditing drives out good auditing'.

Beide vormen komen in elk geval in de Verenigde Staten reeds in zodanige mate voor, dat buitenstaanders daarover met zekere regelmaat publiceren: zie bijvoorbeeld Stevens (1991). De lezer mag op gezag van schrijver dezes aannemen dat deze verschijnselen ook in Nederland niet geheel onbekend zijn.

Daar komt bij dat samenwerkingsverbanden van accountants in binnen- en buitenland hun dienstenpakket trachten uit te breiden door duurzame samenwerking aan te gaan met beoefenaren van andere vrije beroepen; deze samenwerkingsverbanden voeren het zogenaamde 'full-service concept' in hun vaandel. Dit kan in beginsel ongewenste gevolgen hebben voor de onpartijdigheid van de accountants, en daarmee voor de kwaliteit van hun op derden gerichte arbeid. Zo kan de samenwerking met beoefenaren van beroepen die partijdigheid met zich meebrengen, zoals met advocaten, de beroepshouding van accountants beïnvloeden. Maar ook de samenwerking met beroepen waarbij de partijdigheid een geringe of geen rol speelt, zoals bij vele adviseurs, levert in beginsel een bezwaar op. Wanneer een accountant ten aanzien van de goedkeuring van een jaarrekening een moeilijke beslissing moet nemen die kan leiden tot verlies van de controle-opdracht, wordt dit besluit moeilijker naarmate méér collega's uit hetzelfde samenwerkingsverband andersluidende opdrachten van dezelfde cliënt hebben; oneigenlijke overwegingen kunnen dan de beslissing sterker beïnvloeden. Het NIVRA vraagt dan ook in eerdergenoemde discussienota om reacties op de stelling dat er grenzen zijn aan het zogenaamde 'full-service concept'.

De beoefenaren van andere beroepen ervaren de banden met accountants in een samenwerkingsverband eveneens soms als knellend: bekend is de sterke scheiding die enkele jaren geleden binnen Arthur Andersen tot stand gebracht is tussen accountancy en consultancy, voornamelijk op initiatief van de consultants (Stevens, 1991).

Anderzijds ben ik van mening dat een accountant die goede adviezen geeft, in zijn controlefunctie sterk staat tegenover zijn cliënt: bij verschil van inzicht over de jaarrekening zal de cliënt gemakkelijker zwichten omdat hij zijn goede adviseur niet wil missen. Daarom is het verklaarbaar dat in een Nederlandse enquête accountantskantoren met weinig werknemers aangaven dat ze zich positief wisten te onderscheiden van collega-kantoren op het punt 'geven van advies op eigen initiatief' (Leeflang c.s. 1992, p. 159). Of dit feitelijk juist is, valt moeilijk na te gaan, maar de instelling van deze kleine accountantskantoren is in beginsel gezond omdat deze de onpartijdigheid bevordert. Dat ook opdrachtgevers nogal sterk blijken te hechten aan 'persoonlijke binding' (Vriens c.s. 1992, p. 236), behoeft dan ook op zichzelf geen zorg te baren. Een verbod tot het uitoefenen van de 'natuurlijke adviesfunctie', het grotendeels ongevraagd adviseren door de controlerend accountant, is dan ook contraproduktief; een multidisciplinair samenwerkingsverband wordt echter door dit argument nog niet gerechtvaardigd.

De eventuele eliminatie van kwaliteitsverschillen betreffende tolerantie en risico alsmede de begrenzing van het 'full-service concept' kunnen door de beroepsorganisatie in eerste instantie door regelgeving worden verwezenlijkt; deze verschijnselen liggen vast in regelingen met algemene werking binnen respectievelijk tussen samenwerkingsverbanden.

De kwaliteitserosie treedt echter vaak schoksgewijze per opdracht op, bij concrete incidentele gebeurtenissen die veelal onomkeerbaar zijn. De belangrijkste hiervan zijn:

- de overgang van opdrachten, en

- de zogenaamde 'opinion shopping', welke ook in samenhang kunnen vóórkomen.

Deze verschijnselen zijn veel minder goed met algemene regelgeving te beheersen; daarom wordt hieraan in de volgende paragrafen afzonderlijk aandacht gegeven.

\section{Overgang van opdrachten}

Zoals de discussienota (NIvRA 1992) stelt, kan de overgang van opdrachten onder meer voortvloeien uit: 
- de verwachting van een minder onwelgevallige beoordeling van voorgestelde oplossingen voor jaarrekeningproblemen door andere accountants;

- de weigering onregelmatigheden ongedaan te maken;

- de wens tot verlaging van de kosten van de accountantscontrole.

(NIvRA 1992, paragraaf 4.5.)

In een Nederlands onderzoek naar de door opdrachtgevers gegeven redenen voor het wisselen van accountantskantoor (Vriens c.s., 1992) wordt alleen de laatstgenoemde reden specifiek genoemd, met een lage score: 5 uit 81 (Vriens c.s. 1992, p. 259). De twee andere hiervoor genoemde redenen kunnen verpakt zijn met het etiket 'ontevredenheid' (met een score van 25 uit 81), hoewel dat uiteraard niet vaststaat; het moet anderzijds ook niet uitgesloten worden geacht.

Vooropgesteld zij, dat de overgang naar een andere accountant het goed recht van een opdrachtgever is. De normale procedure is tegenwoordig, dat andere accountants in de gelegenheid worden gesteld zichzelf en hun organisaties te presenteren en offerte voor de opdracht uit te brengen.

Dit proces biedt onvoldoende waarborgen tegen kwaliteitserosie. Daarom zou de beroepsorganisatie in de gelegenheid behoren te worden gesteld een onderzoek in te stellen naar de reden van de overgang van de opdracht. Dat onderzoek behoeft natuurlijk niet in alle gevallen een diepgaand karakter te hebben; indien de vertrekkende accountant mededeelt dat de overgang normaal te achten is, bijvoorbeeld als gevolg van gewijzigde eigendomsverhoudingen bij de cliënt, kan verder onderzoek achterwege blijven.

Indien de reden voor de overgang van de opdracht is gelegen in een verschil van inzicht over een jaarrekeningprobleem, zou de mening van de potentieel opvolgende accountant door de beroepsorganisatie moeten worden getoetst, alvorens de opdracht kan worden aanvaard.

Als de reden is gelegen in de aanbieding van een aanzienlijk lagere prijs door de potentieel opvol- gende accountant, zou de beroepsorganisatie de daaraan ten grondslag liggende calculaties moeten toetsen aan de minimum kwaliteitseisen. In dit verband lijkt het zinvol te bevorderen dat degenen die bevoegd zijn de accountant te benoemen, jaarlijks op de hoogte worden gesteld van de kosten van de accountantscontrole.

Indien de reden is gelegen in de onwil om onregelmatigheden ongedaan te maken, zou de beroepsorganisatie slechts toestemming voor de aanvaarding van de opdracht mogen geven indien wordt aangetoond dat de onregelmatigheden alsnog zijn geredresseerd.

Deze vorm van kwaliteitsbewaking is effectiever dan een meer algemene vorm van collegiale toetsing, waarbij de kwaliteit slechts op basis van een 'blinde' steekproef uit de opdrachten beoordeeld kan worden. Indien de beroepsorganisatie bemoeienis heeft met de overgang van opdrachten, wordt de aandacht specifiek gericht op opdrachten waarbij de kwaliteit in beginsel wordt bedreigd.

Dit alles kan niet worden verwezenlijkt zonder een voorschrift dat opdrachten die van andere accountants worden overgenomen slechts met toestemming van de beroepsorganisatie kunnen worden aanvaard. Verdergaande maatregelen zijn denkbaar om in het maatschappelijk verkeer geloofwaardig te maken dat deze bemoeienis van de beroepsorganisatie méér betekent dan een onderonsje tussen accountants die de markt verdelen.

Deze weg wordt helaas vooralsnog geblokkeerd door de overheid, die zich blijkens een recent concept-wetsvoorstel heeft voorgenomen de beroepsorganisatie een zware rol te geven bij de overgang van opdrachten bij onwil onregelmatigheden ongedaan te maken, en dan vervolgens inzage in de documentatie van de beroepsorganisatie te forceren. Daardoor zal de discussie binnen het accountantsberoep over een rol van de beroepsorganisatie bij de overgang van alle opdrachten wel niet snel op gang komen.

\section{Opinion shopping}

Zoals aan het einde van paragraaf 4 van dit artikel is gesteld, is een andere mogelijke oorzaak van 
kwaliteitserosie gelegen in het verschijnsel van 'opinion shopping'. Dit vindt thans in Nederland vooral plaats in de volgende vormen:

- een cliënt, heeft een verschil van inzicht met zijn accountant over een jaarrekeningprobleem en vraagt, bijvoorbeeld via een werkgeversorganisatie, aan andere (samenwerkingsverbanden van) accountants of deze misschien een minder onwelgevallige mening over het vraagstuk hebben; zo ja, dan wordt de eigen accountant hiermee onder druk gezet, met de al dan niet subtiele dreiging tot verandering van accountant;

- een financiële instelling heeft een nieuwe financieringsvorm ontwikkeld en vraagt aan verschillende samenwerkingsverbanden van accountants hun mening over de verwerking hiervan in de jaarrekening, waarbij vooral een uitspraak dat deze financiering buiten de balans kan blijven erg in trek is; zodra een gezaghebbende accountant een dergelijke uitspraak doet, wordt deze als verkoopargument gebruikt;

- ondernemers uit een bedrijfstak komen met hun accountants bijeen om gezamenlijk een gedragslijn voor de verantwoording in de jaarrekening van een voor de bedrijfstak typisch verschijnsel af te spreken.

Bij dit alles is te bedenken dat de vaststelling van normen voor de verantwoording in de jaarrekening toekomt aan bepaalde maatschappelijke organen, en niet aan ad hoc tot stand gekomen combinaties van ondernemers en accountants. In alle beschreven gevallen wordt gezocht naar de meest liberale uitspraak die als gezaghebbend kan worden gepresenteerd, hetgeen gemakkelijk kan leiden tot erosie van de kwaliteit van de verslaggeving.

Het is schrijver dezes bekend dat gezaghebbende samenwerkingsverbanden van accountants deze valkuilen reeds vaak hebben weten te vermijden door onderling overleg op vrijwillige basis. Hoe belangrijk dit ook is, het biedt geen maatschappelijk zichtbare garantie.

Deze praktijken zijn slechts doeltreffend tegen te gaan door accountants te verbieden meningen te geven over vraagstukken in jaarrekeningen die worden gecontroleerd door andere (samenwerkingsverbanden van) accountants. Dergelijke meningen kunnen dan uitsluitend gegeven worden door de beroepsorganisatie, die daar dan ook voor toegerust dient te zijn. Het lijkt zinvol hiertoe gezaghebbende postactieve accountants in te schakelen.

\section{Slot}

Menigeen zal menen dat de in het voorgaande ontvouwde gedachten nogal ver reiken. Te bedenken zij echter dat het publiek in toenemende mate bewust wordt van de commercialisatie van het accountantsberoep; die bewustwording wordt gevoed door boeken als dat van Stevens, en artikelen in veelgelezen bladen als Time en, in eigen land, FEM. Ook heeft het beroep de doorgaande kritiek te verduren van parlementariërs, zij het vooral van de kleur die nog altijd sterk geneigd is tot overheidsingrijpen, zoals Vreugdenhil en Vermeend in eigen land en Dingell en Wyden in de Verenigde Staten. Zijdelings houdt hiermee verband de toename van aansprakelijkstellingen en de eveneens toenemende onverzekerbaarheid daartegen.

Zelfregulering is zowel vaktechnisch als politiek de beste oplossing. Dan zijn echter méér dan marginale maatregelen nodig! Daarvoor is dan weer een sterke beroepsorganisatie vereist.

\section{Literatuux}

Bruyne, A.L. de, De geschiedenis van de beroepsorganisatie der accountants in Nederland 1895-1975, Samsom, 1980.

Kunst, P. en Lemmink, J., Quality Management in Services, Van Gorcum, 1992.

Leeflang, P.S.H., Alkema, S., Rosbergen, E. en Vriens, M., De markt voor accountantsdiensten in Nederland (deel 2). $M A B$, april 1992, pp. 153-161.

NIvRA, Kwaliteit, de nieuwe kleren van de keizer? Discussienota, NIvRA, mei 1992.

Stevens, Mark, The Big Six, Simon \& Schuster, 1991.

Vriens, M., Leeflang, P.S.H., Rosbergen, E. en Wilms, T.J.M., De markt voor accountantsdiensten in Nederland (deel 3), MAB, mei 1992, pp. 224-238.

Vries, Johan de, Geschiedenis der Accountancy in Nederland, Aanvang en Ontplooiing, 1895-1935, Van Gorcum, 1985. 